\title{
INTERAÇÕES VIRTUAIS ENTRE TUTORES E ESTUDANTES NO MOODLE: PROCESSOS EDUCATIVOS EM CONTEXTO DE ESTÁGIO NA EDUCAÇÃO INFANTIL
}

\author{
Luana Zanotto ${ }^{1}$ \\ Aline Sommerhalder ${ }^{2}$ \\ Maria Elisa Nicolielo ${ }^{3}$ \\ Andressa de Oliveira Martins ${ }^{4}$
}

\begin{abstract}
Resumo
$\mathrm{O}$ artigo tem como objetivo identificar processos educativos desencadeados pela troca de $e$ mails internos no Moodle, entre tutoras virtuais e estudantes na disciplina de 'Estágio Supervisionado em Educação Infantil', em um curso de Pedagogia a distância. Aproximar-se desta ferramenta de interação virtual, delega destaque à tecnologia como mediação de processos de ensino e aprendizagem que podem ser lidos a partir da compreensão de práticas sociais. Compreende-se que as interações virtuais revelaram uma relação pedagógica de qualidade, promotoras do acesso legítimo aos conhecimentos científicos no campo da docência na educação infantil. As relações humanas efetivadas colaboraram à construção de vínculos afetivos entre estudantes e tutoras, de modo que a identificação dos processos educativos puderam constituir conhecimentos compartilhados, que transcenderam dúvidas de ordem técnica da disciplina e estimularam a análise crítica da realidade encontrada em estágio.
\end{abstract}

\footnotetext{
${ }^{1}$ Doutoranda em Educação pelo Programa de Pós-Graduação em Educação (PPGE) da Universidade Federal de São Carlos (UFSCar). Endereço: Rodovia Washington Luís, s/n, Jardim Guanabara, São Carlos/SP - Brasil. CEP: 13565-905. E-mail: luanazanotto@yahoo.com.br

2 Docente do Programa de Pós Graduação em Educação (PPGE/UFSCar). Docente do Departamento de Teorias e Práticas Pedagógicas/UFSCar. Doutora em Educação Escolar e Pedagoga. Endereço: Rodovia Washington Luís, s/n, Jardim Guanabara, São Carlos/SP - Brasil. CEP: 13565-905. E-mail: sommeraline@hotmail.com

${ }^{3}$ Mestre em Educação. Pedagoga na rede municipal de ensino na cidade de Pederneiras-SP. Endereço: Rua Prudente de Moraes n. 294, Centro, Pederneiras/SP - Brasil. CEP: 17280-000. E-mail: linicolielo@hotmail.com

${ }^{4}$ Mestranda em Educação pelo Programa de Pós-Graduação em Educação da Universidade Federal de São Carlos. Endereço: Rodovia Washington Luís, s/n, Jardim Guanabara, São Carlos/SP - Brasil. CEP: 13565-905. E-mail: martinsandressa27@yahoo.com.br
} 
INTERAÇÕES VIRTUAIS ENTRE TUTORES E ESTUDANTES NO MOODLE: PROCESSOS EDUCATIVOS EM CONTEXTO DE ESTÁGIO NA EDUCAÇÃO INFANTIL

Palavras-chave: Processos educativos; Tutoria Virtual; Prática Social no trabalho Docente em EaD; Estágio Supervisionado em Educação Infantil

\section{INTRODUÇÃO}

A Educação a Distância (EaD) é uma modalidade de educação que apresenta como característica essencial uma proposta de ensinar e de aprender sem que os docentes e discentes necessitem estar no mesmo local (espaço) e ao mesmo tempo. $\mathrm{Na} \mathrm{EaD} \mathrm{existe} \mathrm{uma}$ distância temporal e física entre estudantes e educadores, assim, nessa modalidade a tecnologia é instrumento de mediação dos processos educativos (NUNES, 2013). Tal modalidade educacional concretiza-se pelos programas computacionais, todavia construída pelo envio e recebimento de mensagens e disponibilização de recursos didáticos específicos para este tipo de ensino, tais como, os livros acessíveis na versão digital, recursos audiovisuais (videoaulas, webconferências, podcasts) disponíveis no Ambiente Virtual de Aprendizagem (AVA), etc.

A partir de suportes tecnológicos, a interlocução ocorre tanto por meio da comunicação sincrônica/simultânea (chat/ sala de bate-papo) quanto pelos meios de comunicação assíncrona (fóruns de dúvidas e de discussões, ferramentas de edição de textos, mensagens, $e$ mails internos do moodle). Nestes moldes, a EaD é uma metodologia da educação que faz uso das tecnologias temáticas, por excelência, bem como pelas conjunturas das suas condições baseadas nas telecomunicações e informática (MILL, 2012). Deste modo, concebe-se que as novas Tecnologias de Informação e Comunicação (TICs) são mediações que oferecem suporte à criação, organização, armazenagem e construção de saberes e conhecimentos, bem como as distintas formas de sociabilidades.

$\mathrm{Na}$ educação a distância, os processos de ensino e de aprendizagem possibilitam a aparição de distintos modos de se relacionar humanamente, mediados pelos ambientes virtuais criados por meio destas TICs. Tais relações humanas ocorrem entre os diferentes sujeitos que compartilham deste espaço de formação, portanto, sendo uma relação entre estudantesestudantes, estudantes-tutores, estudantes-professor e tutores-professor. Assim, nas relações, a busca pela compreensão dos conteúdos está na interação com e entre os saberes e no diálogo entre estes sujeitos. 
ZANOTTO, L.; SOMMERHALDER, A.; NICOLIELO, M. E.; MARTINS, A. O.

Nas distintas relações humanas possibilitadas pela EaD (nível superior) - como um campo único na experiência humana - perpassam a construção de processos de ensinar e de aprender e se dão por meio da prática social de sujeitos em processo de formação universitária. Neste âmago, recorremos a Silva (2004) para compreender que as práticas sociais nascem a partir das relações que são desenvolvidas entre as pessoas, assim têm como principais atores os sujeitos participantes. São nas práticas sociais que os indivíduos interagem com a comunidade em que convivem, assim educam-se por meio deste convívio e relacionamento com as pessoas e com o mundo.

Ao encontro, Oliveira et al. (2014) indicam que as práticas sociais são decorrentes e geradoras das interações entre as pessoas, podendo ocorrer no interior de grupos, instituições, comunidades, etc. Do mesmo modo, “[...] promovem formação para a vida na sociedade por meio dos processos educativos que estas desencadeiam." (OLIVEIRA et al., 2014, p. 34). De tal forma, reconhecemos que por meio das práticas o ser humano conhece o mundo, interage com ele e com os demais sujeitos, significa-o e (re)significa-o, se constrói enquanto sujeito, se abre para o novo, educa-se.

O conceito de práticas sociais também se encontra relacionado ao conceito de cultura (FREIRE, 1987). Para o autor, o cultivo e o reconhecimento da cultura se dão através das relações, sobretudo nas interações humanas. Apoiamo-nos em Fiori (2014) para compreender que cultura é tudo aquilo que o ser humano produz mediante os valores predominantes em uma determinada sociedade fazendo-o constituir o mundo e se constituir. "Todas as atividades humanas, enquanto carregadas de uma significação valorativa (seja econômica, religiosa ou outra) representam dimensões de cultura" (FIORI, 2014, p. 63). Para este autor, a cultura é entendida como valorização do humano e humanização, pois a partir dela, ou seja, das atividades realizadas pelos sujeitos, o sujeito procura Ser Mais, se desenvolver e com isso, se humaniza.

É nesse mesmo sentido que a cultura é significada por Freire (1987). Para ele, cultura é atividade humana produzida e transformada, inicialmente, para a subsistência de homens e mulheres, letrados ou iletrados que, a partir dessa produção, se reconhecem enquanto sujeitos. Por estes aspectos compreendemos que as experiências acadêmicas oportunizadas pela EaD é uma experiência relacional, intersubjetiva, expressa e (re)constrói culturas, é uma prática humana, em que cada estudante também se constitui e se educa nas relações vividas com os outros. Diante disto, as interações virtuais entre eles também se configuram como prática social, quer dizer que nesta própria prática social, a cultura estudantil emerge e é enriquecida, tornando possíveis os processos de ensinar e de aprender. 

EDUCATIVOS EM CONTEXTO DE ESTÁGIO NA EDUCAÇÃO INFANTIL

As práticas sociais compõem uma rede de movimentação cultural, na qual os conceitos e saberes sobre o mundo e cotidianidade estão em contínuo processo de formação, construção e transformação. Compartilhamos as ideias de Oliveira et al. $(2014$, p. 31) ao apontar que "em todas as práticas sociais há processos educativos, portanto, todas as práticas [falamos de práticas humanas, como requer o campo da Educação, dentro das Ciências Humanas] são educativas". As interações entre pessoas, protagonistas das relações concretizadas nas distintas ocasiões geram processos educativos, portanto, todas as práticas humanas, são educativas.

O cultivo e o reconhecimento da cultura e experiências escolares/universitárias dão-se por meio das relações e dos processos educativos desencadeados. A participação em práticas sociais permite colaborar e compreender os processos educativos consolidados, como uma relação dialógica entre os semelhantes e diferentes, numa dinâmica em que um se educa com o outro, em um processo coletivo e colaborativo. Assim, instituem coletivamente uma ordem social que rege as relações entre pares e se afirmam como autoras de suas práticas sociais e culturais.

Os processos educativos possibilitam a formação dos sujeitos que delas participam, situações em que o ser humano está em constante processo de formação, em um movimento contínuo de conhecer e aprender. Nestas relações são construídos novos conhecimentos e, concomitantemente, os processos educativos tornam-se perenes ao longo da vida e em diferentes espaços (OLIVEIRA et al., 2014). Dentre estes espaços, notadamente para o presente artigo, destacamos a educação a distância e, especialmente, a prática social das interações virtuais entre tutores e estudantes.

Neste ínterim, buscamos perceber algumas relações educativas que se consolidam por meio desta prática social realizada por sujeitos em processo de formação universitária, compreendendo que nestas práticas as pessoas vivenciam processos educativos. Os saberes verificados no ambiente virtual - entendido enquanto espaço social virtual/sala de aula - e a construção das experiências tecidas com e entre os estudantes não se afastam da função educativa e transformadora da educação, seja ela presencial ou a distância.

Para este estudo, ressaltamos o e-mail ${ }^{5}$ interno utilizado durante a oferta da disciplina 'Estágio Supervisionado em Educação Infantil', como ferramenta amplamente utilizada na

\footnotetext{
${ }^{5}$ Esta ferramenta não foi pensada a priori como o principal recurso de comunicação obrigatoriamente utilizado nas interações com os estudantes. Tal ferramenta foi se mostrando como a de principal utilização no decorrer da disciplina, de modo que os próprios estudantes demonstraram entendê-la como o recurso mais benéfico e de imediato para esta interação com o seu tutor, sendo os fóruns de dúvidas, as mensagens e o chat (bate-papo),
} 
ZANOTTO, L.; SOMMERHALDER, A.; NICOLIELO, M. E.; MARTINS, A. O.

comunicação/diálogo estabelecido entre professor, tutor e estudantes, mais frequentemente na relação educativa entre os dois últimos agentes, ou seja, tutor virtual e estudantes.

Cabe ressaltar que a disciplina em questão, de relação entre teoria e prática reconhece as instituições de educação infantil como fundamentais no processo de formação de professores, para essa etapa educativa. De acordo com a Resolução n. 02/2015, a teoria e a prática em dialogicidade são elementos básicos para o desenvolvimento dos conhecimentos e habilidades necessários à docência (BRASIL, 2015).

Nos Estágios Curriculares, os estudantes são inseridos em seu campo profissional para aproximar com intencionalidade e envolvimento, conhecer uma realidade, interagir com as pessoas e espaços e adquirir aprendizagens fundamentais para a constituição da sua identidade profissional docente. As experiências cotidianas em instituições de Educação Infantil, por meio de interações com profissionais, crianças e familiares e ações contextualizadas nesses espaços aproxima o futuro docente das práticas profissionais, participando da construção do seu 'ser professor', por meio da reflexão articulada entre teoria e prática, superando a dicotomia entre esses dois elementos formativos.

Segundo Pimenta e Lima (2010), o estágio deveria ser uma oportunidade formativa que o licenciando realiza atividades práticas, mas em um movimento de articulação entre teoria e prática. Para essas autoras, o estágio é teoria e prática e não somente teoria ou prática. Para essa compreensão, as autoras destacam que o estágio deve possibilitar esse conhecer uma realidade, problematizando e engajando-se na análise e questionamento da mesma tomando as teorias como fontes deste exercício reflexivo e investigativo. "O estágio curricular é atividade teórica de conhecimento, fundamentação, diálogo e intervenção na realidade, esta, sim objeto da práxis. Ou seja, é no contexto de sala [...], da escola, do sistema de ensino e da sociedade que a práxis se dá” (PIMENTA e LIMA, 2010, p. 45).

No que se refere à disciplina 'Estágio Supervisionado em Educação Infantil', intenciona-se que os estudantes possam se aproximar de uma realidade de instituição de primeira etapa educativa e sala de creche e/ ou pré-escola pública para conhecer, interagir, aprender, elaborar e desenvolver uma ação educativa com crianças, em parceria com a/o professor/a formador/a, a partir de uma necessidade identificada, analisando e problematizando a realidade encontrada, a partir das teorias aprendidas no curso de Pedagogia. Destaca-se ainda que a disciplina de Estágio é fundamental no processo de construção da sua identidade profissional como professor de educação infantil e do

respectivamente, utilizados em frequência menor. 
INTERAÇÕES VIRTUAIS ENTRE TUTORES E ESTUDANTES NO MOODLE: PROCESSOS EDUCATIVOS EM CONTEXTO DE ESTÁGIO NA EDUCAÇÃO INFANTIL

reconhecimento da especificidade da ação de educar, cuidar e brincar como práticas integradas na ação docente com bebês e crianças pequenas de até 5 anos de idade, nesses espaços coletivos educacionais.

Assim, a referida disciplina ocorreu via ambiente virtual de aprendizagem (AVAMoodle) e, conforme Projeto Pedagógico do Curso de Pedagogia, compõe o quinto período da matriz curricular e possui 130 horas de duração, constituindo-se em componente curricular obrigatório. Destinou-se 30 horas às atividades teórico-práticas, realizadas no AVA por meio da leitura de materiais de estudos (teóricos), análise de vídeos e imagens e desenvolvimento de atividades relacionadas às experiências de vivência do estágio curricular de docência na educação infantil. Como parte prática, foram destinadas 100 horas de estágio para inserções em instituições públicas de educação infantil.

O e-mail, por sua vez, foi compreendido como ferramenta de mediação para interação, incentivo e acompanhamento da aprendizagem on-line deste coletivo. Ao identificar e colocar em tela os processos educativos desvelados pelas trocas de $e$-mails, corroboramos com Mill et al. (2008, p. 121) quando destaca que “[...] embora aparentemente simples, a comunicação entre tutor e alunos é a chave na $\mathrm{EaD}$, pois deve ser clara e objetiva e ao mesmo tempo possibilitar aproximação, calor humano, compartilhamento".

Como contribuição na ampliação das discussões que abordam a utilização de ferramentas e recursos tecnológicos dos ambientes e a importância da interação, colaboração do coletivo nos ambientes virtuais e do 'estar juntos virtualmente' (PRETI, 2003), este estudo estabeleceu a seguinte questão problematizadora: que processos educativos decorreram de interações via $e$-mail entre tutor virtual e estudantes na disciplina 'Estágio Supervisionado em Educação Infantil’, de um curso de Pedagogia EaD?

Assim, delineou-se como objetivo identificar processos educativos construídos na troca de e-mails entre tutoras virtuais e estudantes da referida disciplina de Estágio de um Curso de Licenciatura em Pedagogia, no que tange à compreensão das interações virtuais entre estas pessoas como uma prática social.

A relevância deste estudo está na oportunidade de defesa da existência de processos educativos oriundos de relações afetivas humanas geradas na $\mathrm{EaD}$, sem encontro presencial, legitimando o Moodle como um espaço virtual também gerador de práticas sociais e potencialmente educativo, por suas oportunidades tecnológicas de mediação de relações humanas para difusão e trocas de saberes e conhecimentos científicos, expressão de ideias e argumentações e teorização de práticas pedagógicas. Também se mostra colaborativo na 
ZANOTTO, L.; SOMMERHALDER, A.; NICOLIELO, M. E.; MARTINS, A. O.

socialização e publicação de saberes elaborados entre tutores virtuais e estudantes, em suas respectivas funções, fortalecendo o tutor virtual, assim como os estudantes, como protagonistas em relações pedagógicas em disciplinas de relação entre teoria e prática (como os Estágios) e em cursos de formação de professores, na modalidade de educação a distância.

\section{TRAJETÓRIA METODOLÓGICA}

A trajetória metodológica delineada para a realização deste estudo considerou a abordagem qualitativa de pesquisa (BOGDAN; BIKLEN, 1994), pois se comprometeu a conhecer características dos sujeitos participantes, bem como a compreender relações tecidas entre eles em interações virtuais, especificamente por meio da troca de e-mails, no decorrer de uma disciplina obrigatória de 'Estágio Supervisionado em Educação Infantil', de um curso de Pedagogia: modalidade educação a distância, de uma universidade pública brasileira que aderiu o Sistema Universidade Aberta do Brasil, oferecida no $1^{\circ}$ período letivo (semestre) de 2015.

Para a composição do estudo também foram realizados procedimentos técnicos à pesquisa bibliográfica exploratória, uma vez que este procedimento foi capaz de fornecer material analítico para construção dos resultados e diálogo à luz da literatura.

Compõe o grupo de sujeitos participantes da pesquisa duas tutoras virtuais membros da equipe de trabalho coletivo de tutoria da disciplina. A dupla de tutoras é mestre em Educação e possui dois anos ou mais de exercício de docência na educação infantil e/ou experiência nos anos iniciais do Ensino Fundamental, com incursão de investigação em nível de pósgraduação, no campo da pesquisa com crianças/na infância.

Para além das profissionais, também foram sujeitos participantes 26 graduandos/as do curso de Pedagogia que estavam cursando a disciplina obrigatória. Trata-se de um grupo com idade média entre 20 a 45 anos, pertencentes aos polos de Guarulhos, Cubatão, Itapevi e Tarumã (cidades interioranas do Estado de São Paulo/Brasil). Dentre o grupo, 15\% já concluiu alguma formação em nível superior, enquanto para os demais a formação em Pedagogia apresenta-se como a primeira deste nível. Encontram-se na qualidade de alunostrabalhadores, pais e mães de família.

Como objetos de estudo foram utilizados as mensagens de $e$-mails emitidas e recebidas pelas tutoras e estudantes, sobre os mais diversos assuntos e temas contemplados ao longo da disciplina, como dúvidas conceituais, esclarecimentos de prazos e prorrogação dos mesmos, auxílio à navegação no moodle ou questões explicativas e orientações de como proceder em 
acordo às orientações das Unidades de estudos, especialmente ao proposto pelo Guia de estudos da disciplina e Plano de Estágio na Educação Infantil, bem como pedidos de sugestões para organização pessoal com estudos teóricos e campo prático, ou até mesmo compartilhar impasses vividos pelos seus familiares e/ou cotidiano de vida profissional e pessoal.

Para a análise dos conteúdos das mensagens, com vistas a identificar processos educativos consolidados, seguiram-se algumas etapas conforme suscitadas por Minayo (1998), o qual primeiramente pressupõe a organização dos materiais coletados e identificação de possibilidades de análise; seguido pelo desvendamento de conteúdos presentes nos dados coletados ao discutir com o referencial teórico adotado, o seu potencial agrupamento.

Foram respeitados todos os cuidados éticos no tocante ao consentimento de participação dos sujeitos. Sendo assim, a análise categórica das mensagens é de ciência e autorização das tutoras e estudantes, e os nomes empregados foram fictícios, com o intuito de preservar o sigilo e a identidade dos participantes, seguindo os preceitos éticos de pesquisa com seres humanos.

Com base na proposta deste estudo, o item a seguir apresenta alguns resultados encontrados, trazendo recortes descritivos das mensagens de composição do corpo dos $e$ mails enviados e recebidos pelos sujeitos participantes.

\section{APRESENTAÇÃO E DISCUSSÃO DOS RESULTADOS}

Este item apresenta os resultados, de modo a demonstrar as interações constantes ocorridas via troca de e-mails, propondo uma análise da interlocução entre tutoras e estudantes e processos educativos decorrentes destas - de cunho pedagógico e/ou afetivos com base na rotina constante de atendimento aos estudantes.

Para o presente texto, são apresentados os resultados a partir da análise de um conjunto de mensagens ${ }^{6}$ na íntegra ou fragmentos das mesmas, com o intuito de aprofundar reflexões sobre os distintos processos educativos, recolhendo dados descritivos nas mensagens (TRIVINOS, 2009). Da mesma forma, aguçamos o desenvolvimento de uma ideia sobre como os discentes interagem com as tutoras e interpretam os conhecimentos teóricos

\footnotetext{
${ }^{6}$ Salientamos que nem todas as mensagens recebidas e enviadas aprecem nesta discussão, considerando o respeito às normas de extensão do presente texto. Entretanto, o levantamento e leitura de todos os e-mails nos deram base para compreensão dos processos educativos consolidados.
} 
ZANOTTO, L.; SOMMERHALDER, A.; NICOLIELO, M. E.; MARTINS, A. O.

contemplados na disciplina de 'Estágio em Educação Infantil' com o campo prático (instituição de educação infantil/sala de creches ou pré-escolas) e, para além dele.

De modo geral, observamos que a interlocução entre tutoras e estudantes foi se construindo e se fortalecendo à medida em que estes foram percebendo a disponibilidade das tutoras para atendê-los, expressas em mensagens solícitas e de incentivo ao diálogo horizontal e participativo. No decorrer do primeiro mês de oferta da disciplina, observamos que tal intenção aconteceu por um viés dinâmico e respeitoso, no qual tutoras e estudantes elegeram, de modo indireto e ocasional, o e-mail como espaço privilegiado para interagir, questionar, problematizar e discutir os conhecimentos postos em tela.

Os temas que compunham as primeiras mensagens transitaram pelo universo de exploração do ambiente da disciplina; identificação do tutor virtual responsável, descobertas e exploração das novas ferramentas de postagem das atividades; reconhecimento dos colegas de turma; orientações para o estágio em educação infantil, expressando dúvidas sobre como encontrar e baixar materiais de estudos e vídeos propostos em cada unidade de estudo; conhecer o Plano de Estágio na educação infantil que contempla, entre outras atividades, a aproximação para conhecimento da realidade da pré-escola, identificação de uma necessidade do cotidiano da docência com bebês e/ou crianças pequenas, elaboração e desenvolvimento de uma proposta/ação de intervenção pedagógica e outros documentos relativos à parte prática da disciplina; saberes a respeito dos prazos e critérios das atividades virtuais; e de como seriam registradas as experiências em âmbito prático do estágio.

Nestas trocas, as tutoras foram tomando conhecimento do perfil dos estudantes com os quais interagiam e, assim, identificaram um grupo com graus distintos de envolvimento e compreensão da $\mathrm{EaD}$ e do campo de estudo aprofundado na disciplina. Igualmente heterogêneo em interesses, prospectivas, motivações e concepções sobre o campo teórico e prático do estágio em educação infantil.

A utilização do e-mail como ferramenta à comunicação possibilitou a compreensão sobre os perfis dos estudantes de forma mais alargada, mais direta a respeito destes sujeitos até então desconhecidos, por meio da relação confiável e dialogável que se estabelecia, incorporando a um 'todo de compreensão' mais fecundo. Isso, de acordo com Freire (1987, p. 54), é saber, pois "só existe saber na invenção, na reinvenção, na busca inquieta, impaciente, permanente, que os homens fazem no mundo, com o mundo e com os outros". Aproximar-se das pessoas e de seus saberes significa respeitar o contexto social e cultural dos sujeitos com quem atua, significa reconhecê-los como atores sociais e, na medida do possível, os conhecimentos construídos por eles. 

EDUCATIVOS EM CONTEXTO DE ESTÁGIO NA EDUCAÇÃO INFANTIL

Na mensagem a seguir, a estudante demonstra estar à vontade para expor suas dúvidas:

Desculpe-me a ignorância, mas quando você fala "campo de estágio" está se referindo a inserção no ambiente de uma sala de educação infantil? Se for isso já entrei no campo de estágio, mas se não for gostaria que me explicasse melhor o que significa "campo de estágio" (Mensagem enviada pela estudante Paula à tutora virtual Claudia).

É isso mesmo, o campo de estágio é a instituição na qual você realiza o estágio. Que bom que já iniciou sua inserção (Mensagem enviada pela tutora Claudia à estudante Paula).

Acreditamos que a eleição do $e$-mail à interação entre estudantes e tutoras deveu-se ao fato de que esta ferramenta proporciona maior privacidade para ambos, diferentemente do fórum de dúvidas das unidades de estudos, onde todos os estudantes visualizavam as dúvidas dos colegas.

Para muitos, em primeira formação em nível superior, o estágio em educação infantil foi o primeiro contato com universo das instituições (creches e pré-escolas) que realizam o atendimento integrado de educar e cuidar de bebês e crianças com até 5 anos de idade. $\mathrm{Ou}$ seja, momento em que efetivamente estiveram inseridos na Educação Infantil e em uma realidade de prática docente a ser conhecida e problematizada, à luz das teorias estudadas, exercitando-se na efetivação da relação teoria e prática. Neste sentido, destaca-se que esta disciplina constitui-se na primeira disciplina de estágio obrigatório do referido curso, colaborando de forma privilegiada com a construção da identidade profissional docente e, em especial, na especificidade da docência com bebês e crianças pequenas.

Nestas condições, pelas trocas de $e$-mails percebemos que as aprendizagens advindas do campo prático também foram entendidas como mais proveitosas e mais desafiadoras do que apenas a leitura e discussão de textos. A frase de Cristina relata as vivências exitosas em instituição de educação infantil pública:

[...] apliquei hoje a intervenção pedagógica. Foi muito bom! As crianças se envolveram, curtiram, e a $T R^{7}$ também gostou bastante. As crianças queriam que eu ficasse mais.. Fiquei bem feliz. Já estou começando a sentir por ter que deixá-los daqui a pouco [...] (Mensagem enviada pela estudante Cristina à tutora virtual Antônia).

\footnotetext{
${ }^{7}$ TR (tutor regente) é o nome dado, de acordo com a proposta de estágio do curso (explicitado em Projeto Pedagógico de Curso), para o/a professor/a de classe/sala da escola básica pública que recebe e supervisiona o estudante estagiário/a. Este/a profissional participa, durante esta recepção e supervisão do estudante de um curso de Formação on-line, ofertado com atividades integradas à disciplina de Estágio.
} 
ZANOTTO, L.; SOMMERHALDER, A.; NICOLIELO, M. E.; MARTINS, A. O.

Para Mill et al. (2008), na EaD o tutor virtual é o principal agente responsável por manter a comunicação ativa com os estudantes, por isso, compreendemos que trata-se de uma atividade docente. Consoante os autores, "o tutor virtual é um elemento central no processo educacional e, portanto, a qualidade do seu trabalho é primordial para a aprendizagem do estudante" (MILL et al., 2008, p. 114).

Observamos que o acesso ao Moodle pelas tutoras acontecia diariamente, com vistas em manter um vínculo constante. Tais contatos também possibilitaram o aumento no grau de afinidade e liberdade no diálogo, pois os discentes se sentiam à vontade para utilizar expressões coloquiais, forjando ambientes mais descontraídos e amigáveis, assim como, tornando as relações "palpáveis"/calorosas, as quais fortaleceram a construção de vínculos afetivos e caracterizou com qualidade o trabalho na $\mathrm{EaD}$ como um prática social humanamente educativa.

A dialogicidade e o compartilhar de vivências foram pano de fundo de processos educativos desencadeados, os quais se desvelaram por meio da convivência com os estudantes, uma vez que "na relação de conviver, conhecimentos são colocados à disposição e respeitados num processo de conscientização de todos e de ampliação do conhecimento acerca do que vive" (OLIVEIRA, 2014, p. 44). O excerto abaixo de uma mensagem de $e$-mail revela processos imbuídos em uma relação/educação pautados na dialogicidade:

Olá tutora, tudo bem? Só passei para dizer que é muito bom poder contar com alguém que realmente está atento às nossas angústias. Essa fase de estágio tem sido para mim muito angustiante porque junto com ela me efetivei e comecei a trabalhar como PDI no Município. Para mim é tudo muito novo, pois não tenho experiência, então tem sido muito sofrido as questões de horários, mudança de rotina, atividades de horas complementares, muito difíceis... Por isso, a presença e preocupação de vocês com nossas angústias contam muito. Obrigada (Mensagem enviada pela estudante Amanda à tutora virtual Claudia).

Olá! Fico muito feliz por saber que estou contribuindo com sua formação e caminhando junto com você nessa nova etapa de sua vida. Também já passei por isso e sei como o estágio "mexe" com nossa rotina. Também fico feliz em ver como está se empenhando na disciplina. Com certeza terá muito sucesso ao final dela. Vamos em frente! Abraço (Mensagem enviada pela tutora virtual Claudia à estudante Amanda).

Consideramos essas mensagens importantes, para evidenciar a relação de confiança construída entre estudante e tutora virtual ao longo da disciplina. As disciplinas de estágio 

EDUCATIVOS EM CONTEXTO DE ESTÁGIO NA EDUCAÇÃO INFANTIL

implicam mudanças na rotina diária dos estudantes, dado que o estágio é realizado em escolas públicas de educação básica em horário diurno (com vista em contemplar 100 horas de inserção em cada etapa educativa ou nível de ensino), exigindo assim que eles reestruturem seus horários, conciliando trabalho e estágio, além de terem que se dedicar a produção de diferentes registros reflexivos no AVA (como o diário reflexivo e o relatório de estágio), exigidos pela disciplina.

Sendo assim, o apoio do tutor se faz ainda mais fundamental, pois é comum os estudantes desistirem em razão mesmo da necessidade de organização de estudos e dedicação temporal, em disciplinas de relação teórico-prática. Mesmo não tendo o contato físico e o diálogo presencial, os estudantes conseguiram expor suas dúvidas e angústias e, as tutores, por suas vezes, souberam analisar a situação e agir para contribuir com o sucesso nos estudos do aprendiz.

Sobre o assunto, Mill (2012) afirma que as aprendizagens na educação a distância são construídas principalmente a partir das comunicações estabelecidas e isso valoriza a capacidade de gerar e/ou manter uma rede de comunicação entre os participantes, propiciando a construção coletiva de ideias e saberes em comum. Partindo desses pressupostos, retomamos que as interações entre estes dois segmentos geram processos educativos, novamente compreendendo que o ser humano aprende por meio da relação com os outros e com mundo. Em diálogo, Preti (2003, p. 19) expressa:

[...] muito mais do que recorrendo à mediação tecnológica, é a relação com o(s) outro(s) que possibilita ambiência de aprendizagem. Aprendizagem e educação são processos 'presenciais', exigem o encontro, a troca, a cooperação, a co-laboração, e podem ocorrer mesmo os sujeitos estando 'a distância'.

Outro aspecto emergido desta discussão foram as condições de exiguidade de tempo para estudo e realização das tarefas virtuais e à realização das horas de estágio. Esta escassez de tempo, esporadicamente, fora justificada pelas obrigações relacionadas ao trabalho, pelos afazeres domésticos, afazeres com outros membros familiares como, por exemplo, acompanhamento de pais/avós ao médico e, ainda pelas demandas comunitárias de dia-a-dia. Nas mensagens abaixo, observamos alguns apontamentos relativos à prorrogação dos prazos para postagens de atividades virtuais, concomitantemente ao anúncio de suas demandas particulares: 
ZANOTTO, L.; SOMMERHALDER, A.; NICOLIELO, M. E.; MARTINS, A. O.

mexer no AVA, pois já sou formada em Biologia a distância. Embora eu já seja funcionária pública, não sou professora, sou inspetora, mas estou trabalhando na Secretaria de Meio Ambiente. Enfim, devido a esta dedicação ao concurso, perdi algumas atividades aqui na faculdade e algumas não tive um bom desempenho. Diante da situação, passado o concurso, dediquei-me totalmente a essa matéria. Por esse motivo, estou lendo, mais ainda não li todo o material para fazer essa atividade do estágio... Daria tempo se hoje não fosse o aniversário de um aninho do meu lindo e amado sobrinho, e vamos bater parabéns na casa da minha irmã... e também domingo é a festinha dele e estou envolvida com o corre-corre. Será que poderia aumentar o prazo para a turma? Estou aqui conversando pelo Whats com os colegas e eles também estão um tanto atribulados (Mensagem enviada pela estudante Rita à tutora virtual Antônia).

Nestas ocasiões, a tutora compreendeu as demandas de âmbito pessoal, bem como as demandas da própria organização do curso de Pedagogia (outras disciplinas). Assim, analisou as circunstâncias e formulou mensagem de retorno que buscou incentivar a estudante a significar o grau de prioridade para com as demandas da disciplina. Para este incentivo, foi fundamental a explicação da articulação entre teoria e prática no âmbito de estágio, aguçando a percepção do diálogo existente entre os saberes e fazeres na educação infantil e o compromisso com as crianças e a professora. A tutora ainda explicou que as atividades ocorridas simultaneamente no Moodle se dão em função deste diálogo, por isso, a necessidade de estarem alinhadas com os prazos e realização das atividades.

Para além dos pedidos de prorrogação, na mensagem de Rita percebemos o contexto particular de vida sobre a submissão no concurso, demanda no trabalho e na família. Neste sentido, a tutora dialoga:

[...] compreendo seu envolvimento no concurso e reforço que tentativas desta natureza são de suma importância às suas experiências profissionais e à carreira. Sei que envolve dedicação e horas de estudos, ocupando assim grande parte do seu tempo [...] (Mensagem enviada pela tutora virtual Antônia à estudante Rita).

Mesmo atenta e preocupada em garantir que a estudante atendesse aos prazos, todavia postando uma atividade de qualidade e que refletisse as aprendizagens da docência na educação infantil, promovidas pelo estágio, a tutora não se absteve de expressar suas orientações sobre o âmbito de vida de Rita, assim fomentando o diálogo construtivo em torno dos processos educativos decorrentes da demanda de concursos.

De modo análogo a educação presencial, em que o diálogo, respeito, relação de horizontalidade é essencial para uma educação onde todos são sujeitos do processo, na educação a distância isso também deve ocorrer na relação tutor e estudante. É justamente 
neste tipo de relação que os processos educativos são desencadeados e que os processos de ensino e de aprendizagem são fortalecidos.

Neste sentido, o tutor que se dispõe a ler atentamente as mensagens dos estudantes e, dentro das possibilidades que as regras da disciplina oferecem, pode oportunizar novas chances a ele, todavia, fortalecer a relação de ambos e afirmar a importância do diálogo no contexto educativo. Sobre isso, lembramos Freire (1987) quando afirma que sem diálogo não há comunicação e sem esta não há verdadeira educação.

Com relação à compreensão dos contextos de vida particulares, ainda na ótica freireana, salientamos: "o educador ou a educadora crítica, exigente, coerente, no exercício de sua reflexão sobre a prática educativa ou no exercício da própria prática, sempre a entende em sua totalidade, respeitando alguns limites" (FREIRE, 1992, p. 56). Neste âmago, compreendemos que a falta de tempo e contato contínuo com o objetivo de estudos e realização de estágio corresponde ao universo subjetivo dos estudantes.

Entretanto, segundo Preti (2003), o tutor deve orientar que a falta de uma disciplina e de um hábito mais consolidado de estudo, considerando a necessidade de realização de 100 horas de estágio, em uma disciplina com duração de cinco meses e com prazos estabelecidos para envio de atividades virtuais, podem suscitar inúmeras dificuldades relativas ao universo de compreensão do conteúdo, bem como a não integralização dos créditos na disciplina, pelo não cumprimento de prazos, do Plano de Estágio ou por não atingir as médias de desempenho acadêmico e frequências necessárias.

Identificamos que as dificuldades expressas pelos estudantes não passaram despercebidas pelas tutoras - por uma postura de não reduzir a compreensão do outro. Assim elas buscaram entrar em contato com as tutoras presenciais do polo para explicar a necessidade de acompanhar mais sistematicamente a ida da referida estudante à escola. Além deste apoio e trabalho em equipe, as tutoras esclareciam aos discentes as características da modalidade a distância e de seu funcionamento, o qual exige envolvimento e dedicação aos estudos, comprometimento e sistematização contínua de acesso ao ambiente Moodle da disciplina; bem como frequência ao estágio, na instituição de educação infantil, ressaltando assim os desafios, necessidades de investimento e potencialidades de aprendizagem.

A partir dos processos educativos construídos nas relações entre estudantes e tutoras, observamos resultados de êxito, pois este grupo de estudantes conseguiu alcançar o objetivo de realização de cada etapa da disciplina, realizando ainda incursões reflexivas da relação 
ZANOTTO, L.; SOMMERHALDER, A.; NICOLIELO, M. E.; MARTINS, A. O.

teórica e prática. Em sua fala à sua respectiva tutora, Joana demonstra porque o trabalho em tutoria virtual é muito importante para os estudantes:

Olá, [...] Estou me sentindo muito feliz, foi difícil, mas consegui...[emotion de felicidade]. Abraços, Joana" (Mensagem enviada pela estudante Joana à tutora virtual Claudia).

Em outra semelhante mensagem, Mirian se expressa:

Oi, Antonia. Só agora vi sua mensagem. Obrigada por tudo, pela atenção, pelos feedbacks completos e super construtivos, mas principalmente, obrigada pelo carinho e atenção. Finalizei essa disciplina com a sensação de que deveria ter feito mais, mas a correria do dia a dia me impediu de expressar com palavras os diversos aprendizados que as crianças do estágio me proporcionaram. Como você sempre diz, vamos em frente! Beijos Mirian (Mensagem enviada pela estudante Mirian à tutora virtual Antônia).

Neste aspecto, as tutoras virtuais envolvidas se sentiram sensibilizadas e motivadas a seguir com sua atuação docente, pois terminada a atuação nesta disciplina ficou-se o desejo em continuar a criar e gerar beleza e sentido no trabalho de tutoria, sobretudo, buscando ressignificar a EaD como meio profícuo à busca de novos caminhos e novos olhares que contribuam na construção de uma educação superior de melhor qualidade formativa para todos os brasileiros, especificamente, no que tange ao acesso legítimo ao conhecimento científico da profissão de pedagogo, e em especial da docência em educação infantil. Somado a isso, é necessário investir esforços para reconhecimento e valorização dos tutores virtuais como profissionais que também são docentes, em cursos na modalidade de educação a distância.

Por este viés, ainda pensamos que é necessário partilhar, tanto na educação a distância como na presencial, da criação de outras sensibilidades, de outras maneiras pessoais e coletivas de ser e viver, de pensar, de sentir e de, afinal, partilhar a vida nesta prática social de formação universitária a distância.

\section{CONSIDERAÇÕES FINAIS}

Com base nos resultados apresentados compreendemos a $\mathrm{EaD}$ como um sistema educativo que possibilita atendimento educacional e formação profissional de qualidade, acesso legítimo aos conhecimentos científicos, por meio dos programas das disciplinas, com suas ementas, objetivos e conteúdos, além de se constituir como uma forma de criação de 
vínculos afetivos e processos educativos que auxiliam o convívio em sociedade, com base numa educação mais humanizadora (FREIRE, 1987).

Deste modo, acreditamos que a finalidade última de todo o conhecimento, propagado de modo virtual ou presencial é a de buscar, criar, consolidar, desmontar, rebuscar e recriar respostas às verdadeiras necessidades da condição humana.

Para Brandão (2014, p. 13), "assim como todas as outras práticas sociais de vocação humanista, a ciência e a educação que desejamos praticar [...] devem partir desde o lugar social da comunidade humana concreta e cotidiana". Os processos educativos surtidos na relação pedagógica e virtual entre tutoras e estudantes, via e-mail do moodle, estiveram sustentados nos princípios pedagógicos da disciplina e, igualmente, nos contextos de vida particulares dos estudantes, de modo que estes também sejam protagonistas do seu próprio processo formativo e na construção do saber no universo da academia.

Além disto, na interação via e-mail, os estudantes demonstraram interconectar o aprendido na parte teórica da disciplina com o que estavam aprendendo em outra realidade, sobretudo no campo de estágio de educação infantil, refletindo, aprendendo a docência para bebês e crianças pequenas em creches e ou pré-escolas e problematizando uma realidade profissional a partir do conhecimento científico desenvolvido na disciplina de 'Estágio em Educação Infantil'.

Esperamos que os/as tutores/as e outros professores e pesquisadores que realizem a leitura deste artigo considerem o e-mail como recursos tecnológico mediador e fortalecedor de vínculos construídos na $\mathrm{EaD}$, não somente como instrumento para envio/transmissão de informações técnicas do andamento da disciplina e neste caso, do estágio em educação infantil ou dúvidas nas tarefas propostas em ambientes virtuais, mas para estreitar relações e desencadear processos humanizadores que também educam para a vida em convívio social, ainda que a distância.

A expectativa formativa é que novas relações afetivas e educativas se estabeleçam na relação tutor e público - estudantes de Pedagogia em cursos na modalidade de educação a distância, beneficiando ações de conhecimentos e saberes que possam ser transpostos para outros segmentos de convívio em sociedade, oportunizando ao estudante futuro/a professor/a condições reais para participar como principal autor/a na qualidade de sua formação e atuação no mundo.

Defendemos a necessidade de uma educação a distância cujo sentido seja o de recriar continuamente verdadeiras comunidades aprendentes, sendo unidades dentro e fora dos 
ZANOTTO, L.; SOMMERHALDER, A.; NICOLIELO, M. E.; MARTINS, A. O.

ambientes virtuais de aprendizagem, geradoras de saberes, e de maneira crescente e sem limites, abertas ao diálogo e a intercomunicação. Parafraseando Silva (2004, p. 187) “a educação em seu sentido mais demoradamente humano, não gera habilidades e competências [...]. Bem mais além, ela cria conectividades, um alicerce, um chão sobre o qual se pisa ao caminhar e acima do qual resta construir toda a casa do ser".

Por fim, o presente artigo anuncia a necessidade de produção de outros trabalhos científicos que façam aproximações sobre o aprofundamento da compreensão das implicações para os processos de ensinar e de aprender decorrentes das relações pedagógicas virtuais em disciplinas regulares de cursos de formação de professores, que ocorrem tendo como suporte ferramentas tecnológicas e, especialmente em contextos de oferta de Estágios Curriculares.

\title{
VIRTUAL INTERACTIONS BETWEEN TUTORS AND STUDENTS IN MOODLE: EDUCATIONAL PROCESSES IN CONTEXT OF INTERNSHIP IN EARLY CHILDHOOD EDUCATION
}

\begin{abstract}
The article aims to identify educational processes triggered by the exchange of internal emails in Moodle, between virtual tutors and students of discipline 'Supervised Internship in Early Childhood Education', in a pedagogy of distance learning course. Approaching this virtual interaction tool, delegates highlighted technology as mediation teaching and learning processes that can be read from the understanding of social practices. It is understood that virtual interactions revealed a pedagogical relationship quality, promoting the legitimate access to scientific knowledge in the field of early childhood education. Human relations effect collaborated to build emotional bonds between students and tutors, so that the identification of educational processes could be shared knowledge that transcended questions of technical discipline and order encouraged critical analysis of reality found in stage.
\end{abstract}

Keywords: Educational Processes; Virtual tutoring; Social work practice in Teaching in Distance Education; Supervised Internship in Early Childhood Education 
INTERAÇÕES VIRTUAIS ENTRE TUTORES E ESTUDANTES NO MOODLE: PROCESSOS EDUCATIVOS EM CONTEXTO DE ESTÁGIO NA EDUCAÇÃO INFANTIL

\title{
INTERACCIONES VIRTUALES ENTRE TUTORES Y ESTUDANTES NO MOODLE: PROCESOS EDUCATIVOS EN CONTEXTO DE PRÁCTICAS CURRICULARES NA EDUCACIÓN INFANTIL
}

\begin{abstract}
Resumen
El artículo tiene como objetivo identificar los procesos educativos provocados por el intercambio de correos electrónicos internos en Moodle, entre tutores virtuales y estudiantes de la disciplina 'prácticas supervisadas en Educación Infantil', en un curso de pedagogía a distancia. Acercarse a esta herramienta de interacción delega la tecnología como la enseñanza de la mediación y los procesos de aprendizaje que se puede leer desde la comprensión de las prácticas sociales. Se entiende que las interacciones virtuales revelaron una calidad de relación pedagógica, promoviendo el acceso legítimo al conocimiento científico en el campo de la educación infantil. Efecto de las relaciones humanas colaboraron para construir vínculos emocionales entre los estudiantes y profesores, por lo que la identificación de los procesos educativos se podría compartir el conocimiento que trasciende las cuestiones de aportes técnicos y para el análisis crítico de la realidad alentado a que se encuentra en fase.
\end{abstract}

Palabras-claves: Procesos Educativos; Tutoría virtual; Práctica del trabajo social en Magisterio en Educación a Distancia; Prácticas Curriculares Supervisadas en la Educación Infantil

\section{REFERÊNCIAS}

BRASIL. Resolução n. 02/2015. Conselho Nacional de Educação. Ministério da Educação. Diretrizes Curriculares Nacionais para a formação inicial em nível superior (cursos de licenciatura, cursos de formação pedagógica para graduados e cursos de segunda licenciatura) e para a formação continuada. Brasília: CNE/MEC, 2015. Disponível em:

<http://portal.mec.gov.br/>. Acesso em: 11 de Nov. 2016.

BOGDAN, R. C.; BIKLEN, S. K. Investigação Qualitativa em Educação. Porto: Porto Editora, 1994. 
ZANOTTO, L.; SOMMERHALDER, A.; NICOLIELO, M. E.; MARTINS, A. O.

BRADÃO, Carlos Rodrigues. Prefácio: Perguntas, pesquisas. Para quem? Para quê? In: OLIVEIRA, M. W.; SOUSA, F. R. (Orgs.). Processos Educativos em Práticas Sociais: pesquisas em educação. São Carlos: EdUFSCar, 2014.

FIORI, Ernani Maria. Conscientização e Educação. In: BRASIL. Ministério da Saúde. II Caderno de Educação Popular em Saúde. Brasil: Ministério da Saúde, 2014.

FREIRE, Paulo. Pedagogia do oprimido. 17. ed. Rio de Janeiro: Paz e Terra, 1987.

Pedagogia da esperança: um reencontro com a Pedagogia do oprimido. São Paulo: Paz e Terra, 1992.

MILL, Daniel. Docência Virtual. São Paulo: Papirus, 2012.

MILL, D. et al. O desafio de uma interação de qualidade na educação a distância: o tutor e sua importância nesse processo. Cadernos da Pedagogia, São Carlos: UFSCar; São Carlos, v. 2, n. 4, p. 112-126, ago./dez. 2008.

MINAYO, Maria C. S. Pesquisa Social: teoria, método e criatividade. 10. ed. Petrópolis: Vozes, 1998.

NUNES, Vanessa B. O papel do tutor na educação a distância: como tem sido concebido pelas instituições de ensino? In: CONGRESSO INTERNACIONAL ABED DE EDUCAÇÃO A DISTÂNCIA, 19.; 2013, Salvador. Anais... Salvador: ABED, 9-12, set. 2013. p. 81-91.

OLIVEIRA, Maria W. de. Pesquisa e trabalho profissional como espaços e processos de humanização e de comunhão criadora. Cadernos CEDES, Campinas: Unicamp, v. 29, n. 79, p. 309-321, set./dez. 2009.

OLIVEIRA, M. W. et al. Processos educativos em práticas sociais: reflexões teóricas e metodológicas sobre pesquisa educacional em espaços sociais. In: REUNIÃO ANUAL DA ANPED, 32., 2009, Caxambu. Anais... Caxambu: ANPEd, 4-7, out. 2009. p. 1-17.

PIMENTA, S. G.; LIMA, M. S. L. Estágio e Docência. 6. ed. São Paulo: Cortez, 2010.

PRETI, Oreste. O estado da arte sobre "tutoria": modelos e teorias em construção.

Pcientífica, Cuiabá: UFMT, v. 1, 2003. Disponível em:

<http://www.uab.ufmt.br/uab/images/artigos_site_uab/tutoria_estado_arte.pdf >. Acesso em: 05 de Mai. 2016.

SILVA, Petronilha B. G. Aprender a conduzir a própria vida: dimensões do educar-se entre afrodescendentes e africanos. In: BARBORA, L. M. A.; SILVA, P. B. G.;

SILVÉRIO, V. R. De preto a afro-descendente: trajetos de pesquisa sobre relações éticoraciais no Brasil. São Carlos: EDUFSCar, 2004.

TRIVIÑOS, Augusto N. S. Introdução à pesquisa em ciências sociais: a pesquisa qualitativa em educação. 1. ed. São Paulo: Atlas, 2009. 
INTERAÇÕES VIRTUAIS ENTRE TUTORES E ESTUDANTES NO MOODLE: PROCESSOS EDUCATIVOS EM CONTEXTO DE ESTÁGIO NA EDUCAÇÃO INFANTIL 